\title{
THE INFLUENCE OF CARBON FILLERS ON THE ELECTRIC CONDUCTIVITY OF EPOXY RESIN AND ITS SUBSEQUENT SURFACE MODIFICATION
}

\author{
Lenka HÝLOVÁ, Jiří BÁRTA, Viktorie WEISS, Martina PAZDEROVÁ \\ Czech Aerospace Research Centre, Prague, Czech Republic, EU, \\ hylova@vzlu.cz,jiri.barta@vzlu.cz,weiss@vzlu.cz,pazderova@vzlu.cz
}

https://doi.org/10.37904/metal.2019.875

\begin{abstract}
This article deals with the reinforcement of epoxy resin with different carbon fillers in various concentrations. The properties observed in this paper were electric conductivity, hardness and chemical and electrochemical plating. The data obtained from the measurements of electric conductivity and hardness were subsequently examined and discussed.
\end{abstract}

Keywords: Epoxy resin, carbon fillers, electric conductivity, surface modification

\section{INTRODUCTION}

Epoxy resin belongs to the polymer group that is characterized by low molecular weight and the content of more than one epoxide group. Polymer is a macromolecular compound created from units of varying or same monomers. Polymers can be divided into thermoplastic and thermoset. Thermoplastics can be re-processed and moulded into new shapes again using heat, while thermosets cannot be moulded again due to the crosslinking process that occurs during curing. Epoxy resin was discovered by Prileschjew in 1909. It is a resin in which the curing is enabled by various curing agents via numerous curing reactions. Final properties of epoxy resin depend on the unique combination of the resin type and the curing agent. The epoxy resin exhibits great material properties such as high strength and electrical insulation, good chemical and heat resistance and adhesion to many substrates, low shrinkage and toxicity, low cost, etc. Furthermore, it possesses fatigue strength superior to aluminium alloy and excellent compatibility with all common fillers, while also being usable at temperatures up to $175^{\circ} \mathrm{C}$. Because of these properties the epoxy resin is frequently used in wide range of fields for the production of fibre-reinforced composites, high-performance coatings, encapsulating materials, general-purpose adhesives. On the other hand, the disadvantages of epoxy resin are delamination, inherent brittleness and low fracture toughness [1-2]. Therefore as was aforementioned, the epoxy resin is in many instances reinforced with numerous kinds of fillers. After the addition of fillers, the newly created compound offers the advantages of a new material. The epoxy resin supplemented with nano-fillers creates a nanocomposite structure which is widely used in both industrial and academic fields for its diversity in potential applications. The nano-fillers (usually 1-100 $\mathrm{nm}$ ) affect the matrix material properties because the quantum confinement on optical, thermal and electrical properties becomes relevant at this level of particle size. Another important property of nano-materials is its high fraction of the atoms on their surface, where the asymmetrical forces influence the surface tension and the related pressure can cause the change of bond length in crystals and further change the thermal, electrical and mechanical properties [3]. Considering the epoxy resin is an electric insulator and possesses great mechanical properties, there is an effort to create the composite with epoxy resin matrix which would be electrically conductive. The addition of 0.5 and $1 \mathrm{wt}$. \% graphene particles to the epoxy resin has a positive effect on the electric resistivity of the material without influencing the tensile strength. The evaluation showed that the electric resistivity decreased more than two orders of magnitude [4]. This study also concentrated on the epoxy-graphene and epoxy-carbon nano-fibre composites and showed that the compressive load has a negligible effect on the electric conductivity [5]. On the other hand, it was found that the electric conductivity displayed greater values (up to the 13 orders of magnitude) in nanocomposites comprised of core-shell carbon foam with template-coated graphene than in the pure epoxy resin. 
[6]. The effect on the electric conductivity induced by the addition of carbon nano-tubes (with various aspect ratios dispersed by sonication and high speed shear force) in the epoxy resin was also studied. The content of fillers was 0.03 and 0.5 wt. \%. It was found out that the percolation threshold of electric conductivity decreased with the increase of the carbon nanotube aspect ratio and the lowest one was approximately 0.05 wt. \% [7]. Other article focused on the electric conductivity dealt with the reinforcement of epoxy resin with the graphene. When the concentration of graphene was $1.38 \mathrm{vol}$. \%, the electric conductivity was increased by 7 orders of magnitude in comparison to the pure epoxy resin [8]. This study inquired about the influence of carbon microfibers and carbon nano-fillers on the electric conductivity of epoxy resin and its subsequent modifications altered by metallization.

\section{EXPERIMENTAL}

The epoxy resin used was a liquid blend of Araldite $^{\odot}$ LY5052 and the hardener Aradur ${ }^{\odot} 5052$ (both Huntsman Advanced Materials $\mathrm{GmbH}$, Switzerland). Commercially-available carbon fibres, CARBOBYK-9810 (BYKChemie GmbH, Germany), and thin multi-walled carbon nanotubes (MWCN) NANOCYL $® N C 7000^{\mathrm{TM}}$ (Nanocyl SA, Belgium, prepared by Catalytic Chemical Vapor Deposition (CCVD) process), were employed as fillers. Different types of mixing the particles were compared for the best overall conductivity. Nanocyl particles underwent treatment by sonication (dipping Ti probe with $300 \mathrm{~W}$ power, 2 minutes with 4 cycles of pulse sequence), Thinky mixer (Thinky Mixer ARE-310, twice mixing $2000 \mathrm{rpm} 20 \mathrm{~s}+$ defoaming $1000 \mathrm{rpm} 10 \mathrm{~s}$, sonication 2 minutes), and dispersing machine (Dispermat CA60-M1, $9600 \mathrm{rpm} 30 \mathrm{~min}$, cooled to $7{ }^{\circ} \mathrm{C}$ by water, defoaming). Two and three $\mathrm{mm}$ thick sheets $100 \mathrm{~mm}$ long and $100 \mathrm{~mm}$ wide were prepared by loading the mixtures into form and defoaming by vacuum pump. After 24 hours, the samples were cured at $70{ }^{\circ} \mathrm{C}$ for 5 hours. Fillers were applied in rising concentration from 0.5 to $2 \%$. In text, the samples are marked MCF milled carbon fibers and MWCN -multi-walled carbon nanotubes according to mixing technique: sonication S, thinky mixer - TM and dispersion - D. The number following the letter indicates the filler content in wt. \%; i.e. D 0.5 means MWCN dispersion with $0.5 \%$ of filler. Resistivity was determined by high resistance meter Keysight B2980A with N1424A resistivity cell attached (Keysight Technologies, USA). High resistance meter was programmed to directly show value of resistivity in $\Omega . \mathrm{cm}$ according to calculation from electrode size parameters. All samples were fixed in resistivity cell by $3 \mathrm{~kg}$ of pressure. Measurements were carried out at least 30 times.
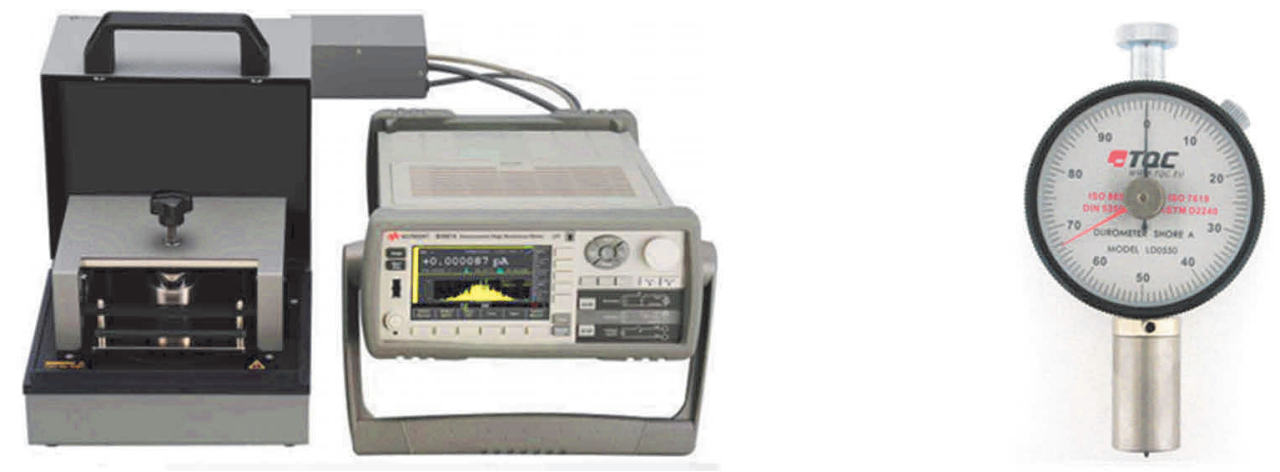

Figure 1 Illustrative pictures of measuring devices - High resistance meter Keysight B2980A with N1424A resistivity cell (left); Shore D hardness meter (right)

The hardness of samples' surfaces was measured by Shore D hardness meter (TQC, Germany) according to ISO 868. Measurements were carried out at least 30 times. The samples were activated as described in Shipley process. As a first step, samples were rinsed in low acidic detergent solution for 1 minute, second step followed - activation by acidic etching in low concentrated $\mathrm{H}_{2} \mathrm{SO}_{4}$ and $\mathrm{HF}$, each for 1 minute. After each step, all samples were heavily rinsed in deionized water. Sensitization was done in solution of $\mathrm{PdCl}_{2}$ with $\mathrm{SnCl}_{2}$, 
$\mathrm{NaCl}$ and acidized by $\mathrm{HCl}$ for 3 minutes. Peptized samples were metallized by electroless plating in bath containing $\mathrm{CuSO}_{4} .5 \mathrm{H}_{2} \mathrm{O}$, EDTA, NaOH ( $\mathrm{pH}$ 8-10) and addition of $\mathrm{NaH}_{2} \mathrm{PO}_{2}$ for 20 minutes. After rinsing, samples were attached by clamp in acidic $\left(\mathrm{H}_{2} \mathrm{SO}_{4}\right)$ solution of $\mathrm{CuSO}_{4} .5 \mathrm{H}_{2} \mathrm{O}$ and $\mathrm{NaCl}$. As anode stainless steel was used and the galvanic process was carried out at current density $1.8 \mathrm{~A} / \mathrm{dm}^{2}$.

\section{RESULTS AND DISCUSSION}

\subsection{Surface Electric Resistivity}

After surface electric resistivity measurement, the results of pure epoxy resin and the epoxy resin reinforced with various types of carbon fillers with different concentrations, were compared.
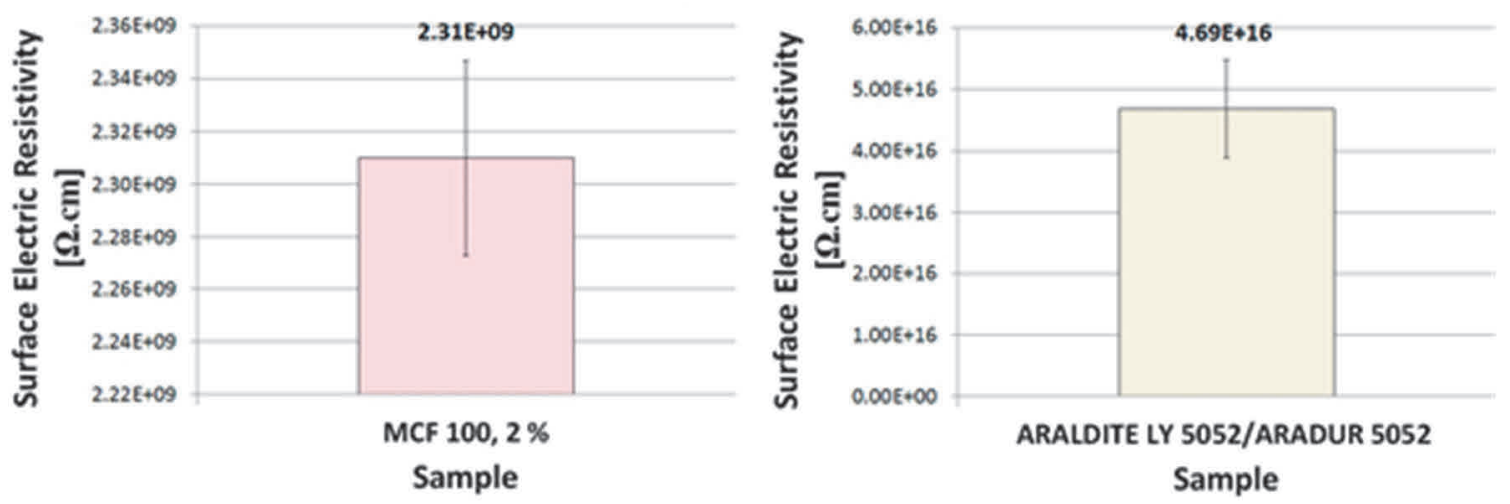

Figure 2 Surface electric resistivity of the sample MCF 100, $2 \%$ and pure epoxy resin

In Figure 2, the surface electric resistivity of pure epoxy resin is displayed. The value is around $4.69 \cdot 10^{16} \Omega . \mathrm{cm}^{1}$ From the measured results, it is the highest value, which shows the highest surface electric resistivity. In Figure 2 it is possible to see, how the reinforcement of epoxy resin with $2 \%$ of carbon micro fibres lowered significantly the surface electric resistivity in comparison to the pure one.

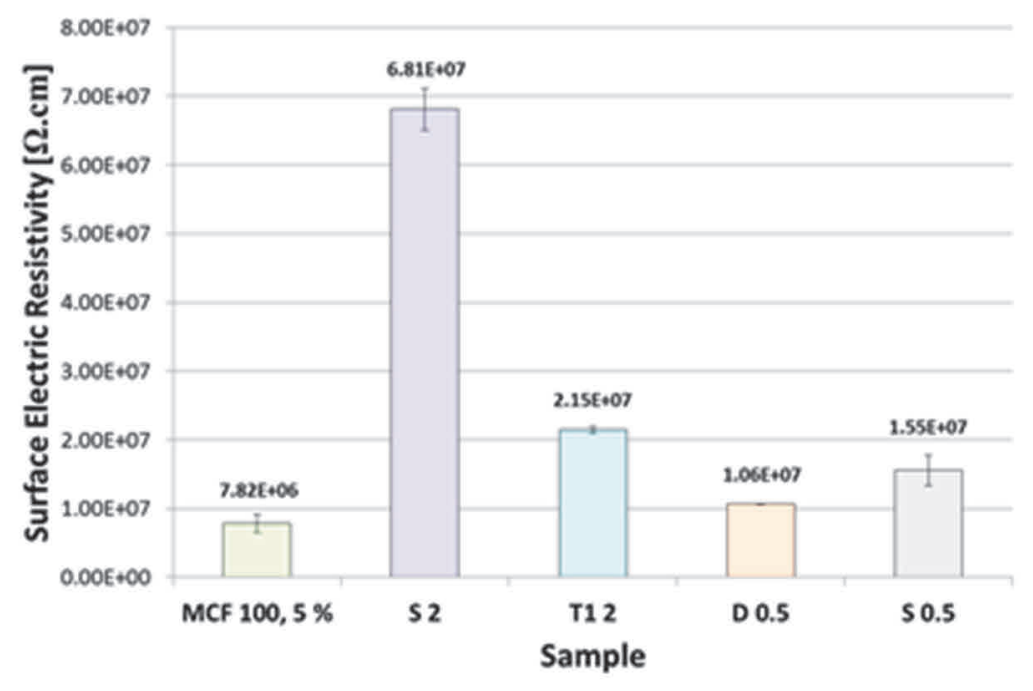

Figure 3 Surface electric resistivity of the samples MCF 100, 5 \%, S 2, T1 2, D 0.5 and S 0.5

From Figure 3 it is clear, that after addition of higher concentration of carbon micro fibres or multi-walled carbon nanotubes in the concentration of 0.5 and $2 \%$, the surface electric resistivity dropped to the orders 
of magnitude of $\mathrm{M} \Omega . \mathrm{cm}$, which is in comparison with the pure epoxy resin (P $\Omega . \mathrm{cm})$ by 9 orders of magnitude lower. As a best level it is possible to consider carbon micro fibres in the concentration of $5 \%$ because of the lowest surface resistivity value of $7.82 \cdot 10^{6} \Omega . \mathrm{cm}$.

\subsection{Volume Electric Resistivity}

Measurement of volume electric resistivity determined the resistivity throughout the volume of the samples.

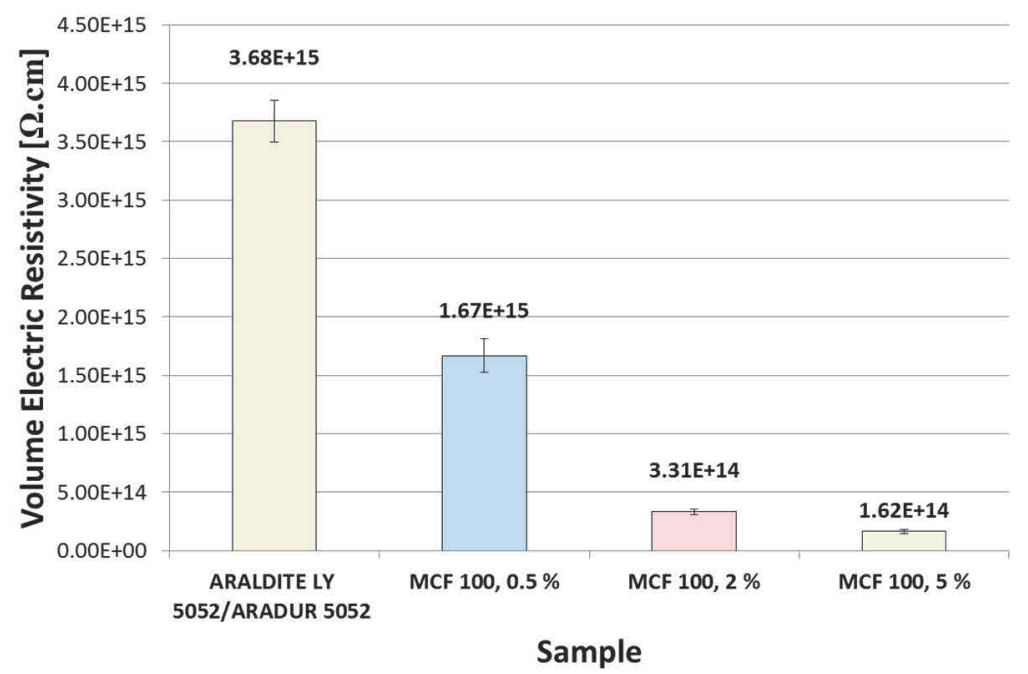

Figure 4 Volume electric resistivity of pure epoxy resin, MCF 100, 0.5 \%, MCF 100, $2 \%$ and MCF 100, $5 \%$

The value of the volume electric resistivity of pure epoxy resin in Figure 4 shows the material properties of pure epoxy resin as a pure insulator. After addition of carbon micro fibres into the epoxy resin matrix, the volume electric resistivity is very close to the pure epoxy resin as it is visible in Figure 4. It is possible to formulate, that the addition of these fibres did not affect the volume electric resistivity significantly.

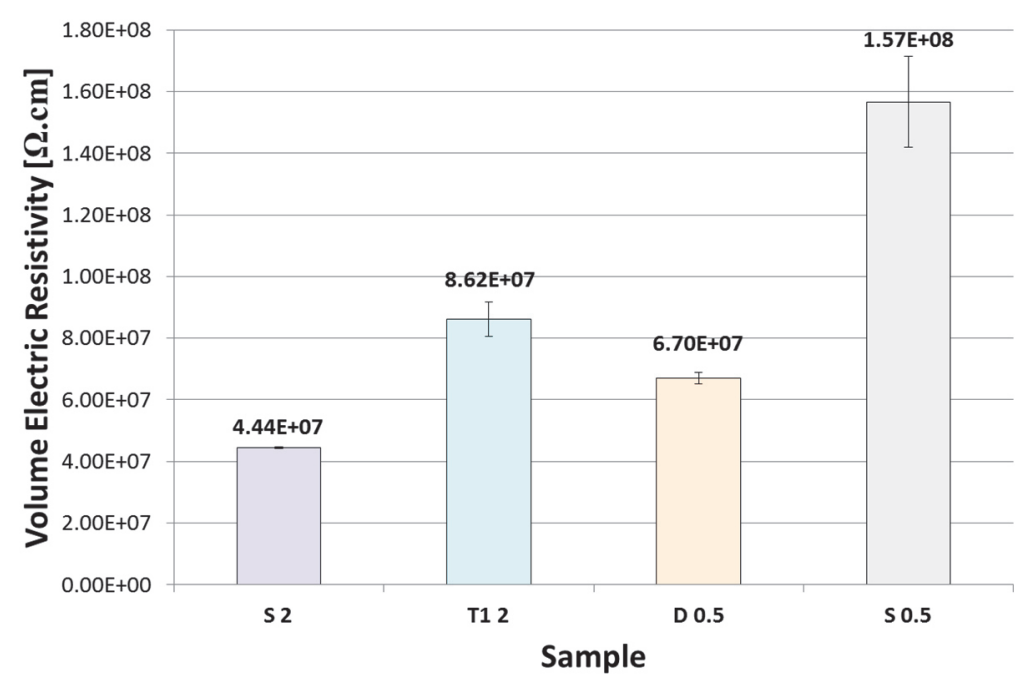

Figure 5 Volume electric resistivity of the samples S 2, T1 2, D 0.5 and S 0.5

To obtain the lowest volume electric resistivity of the sample, the most efficient way is to use as a filler multiwalled carbon nanotubes in the concentration of $2 \%$ in comparison to pure epoxy resin and others samples, as is shown in Figure 5. 


\subsection{Shore D}

Hardness test measurement is important for the evaluation of the mechanical behaviour of various reinforced samples to comparison with the pure one.

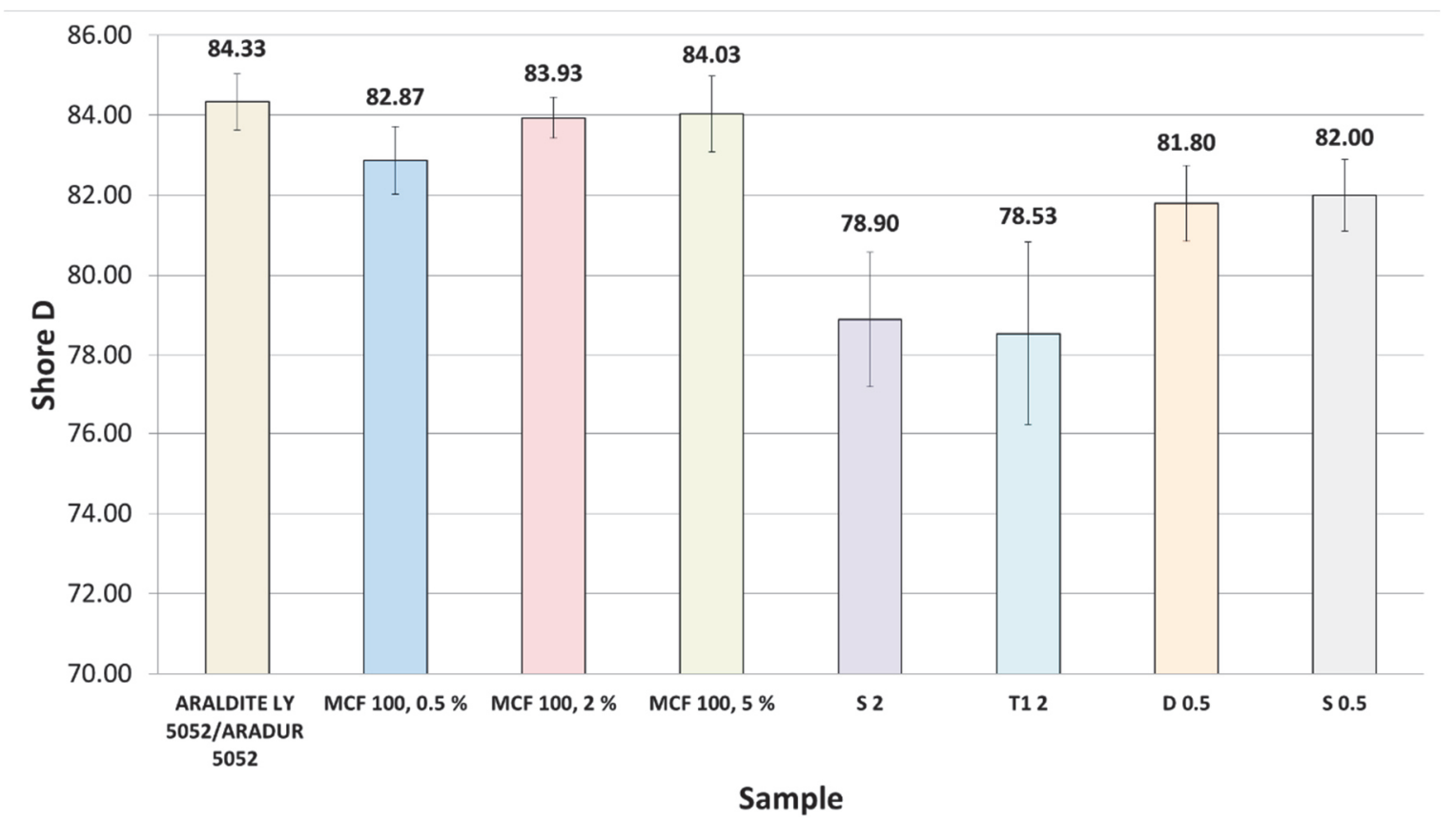

Figure 6 Shore D hardness of the samples of pure epoxy resin, MCF 100, 0.5\%, MCF 100, $2 \%$, MCF 100, $5 \%$, S 2, T1 2, D 0.5 , S 0.5

From Figure 6 it is clear, that the reinforcement of epoxy resin with multi-walled carbon nanotubes caused the biggest increase of hardness. The values of pure epoxy resin and epoxy resin reinforced with carbon micro fibres are comparable.

\section{CONCLUSION}

As far as we can say, the amount of nanoparticles in our samples was not sufficient for direct galvanic treatment. From results we assume that $0.5 \%$ MWCN content with proper dispersion method (D - dispersion with sonication) is sufficient for saturation of conductivity and increase of hardness. $0.5 \% \mathrm{MWCN}$ dispersed and sonicated creates filler content with reasonable increase in conductivity, hardness and feasibility of composite preparation. Further study of metallized samples' properties will be a subject of future research.

\section{ACKNOWLEDGEMENTS}

This project result was developed within the institutional support of the Ministry of Industry and Trade of the CR directed to the development of research organizations.

\section{REFERENCES}

[1] BELLO, Sefiu A., AGUNSOYE, Johnson O., HASSAN, Suleiman B., ZEBASE KANA, Martiale M. and RAHEEM, A. Isiaka. Epoxy Resin Based Composites, Mechanical and Tribological Properties: A Review. Tribology in Industry. 2015. vol. 37, no. 4, pp. 500-524.

[2] JIN, Fan-long, LI, Xiang and PARK, Soo-Jin. Synthesis and application of epoxy resins: A review. Journal of Industrial and Engineering Chemistry. 2015. vol. 29, pp. 1-11. 
[3] LIU, Shan, CHEVALI S. Venkata, XU, Zhiguang, HUI, David and WANG Hao. A review of extending performance of epoxy resins using carbon materials. Composites Part B. 2018. vol. 136, pp. 197-214.

[4] WENTZEL, Daniel, MILLER, Sandi and SEVOSTIANOV, Igor. Dependence of the electrical conductivity of graphene reinforced epoxy resin on the stress level. International Journal of Engineering Science. 2017. vol. 120, pp. 63-70.

[5] GOVOROV, Alexey, WENTZEL, Daniel, MILLER, Sandi, KANAAN, Ahmed and SEVOSTIANOV, Igor. Electrical conductivity of epoxy-graphene and epoxy-carbon nanofibers composites subjected to compressive loading. International Journal of Engineering Science. 2018. vol. 123, pp. 174-180.

[6] LI, Shuang, HAN, Xiao, ZHAO, Xiaoran and ZHAO, Yan. High-efficiency enhancement on thermal and electrical properties of epoxy nanocomposites with core-shell carbon foam template-coated graphene. Composites Part $A$. 2019. vol. 120, pp. 95-105.

[7] ZHANG, Yuxuan, LI, He, LIU, Peng and PENG, Zongren. Study on Electrical Properties and Thermal Conductivity of Carbon Nanotube/Epoxy Resin Nanocomposites with Different Filler Aspect Ratios. 2016 IEEE International Conference on High Voltage Engineering and Application (ICHVE) [online]. 2016. [viewed 2019-04-05]. Available from: DOI: 10.1109/ICHVE.2016.7800771.

[8] ZHENG, Wankun, CHEN, Wen'ge, ZHAO, Maiqun, REN, Shuxin and FU R. Yongqing. Interfacial structure and mechanism for strengthening and enhanced conductivity of graphene/epoxy nanocomposites. Polymer. 2019. vol. 163. pp, 171-177. 